\title{
Comparative studies of glycosylphosphatidylinositol-anchored high-density lipoprotein-binding protein 1: evidence for a eutherian mammalian origin for the GPIHBP1 gene from an $L Y 6$-like gene
}

\author{
Roger S. Holmes • Laura A. Cox
}

Received: 2 June 2011/Accepted: 21 September 2011/Published online: 18 October 2011

(c) The Author(s) 2011. This article is published with open access at Springerlink.com

\begin{abstract}
Glycosylphosphatidylinositol-anchored highdensity lipoprotein-binding protein 1 (GPIHBP1) functions as a platform and transport agent for lipoprotein lipase (LPL) which functions in the hydrolysis of chylomicrons, principally in heart, skeletal muscle and adipose tissue capillary endothelial cells. Previous reports of genetic deficiency for this protein have described severe chylomicronemia. Comparative GPIHBP1 amino acid sequences and structures and GPIHBPI gene locations were examined using data from several mammalian genome projects. Mammalian GPIHBP1 genes usually contain four coding exons on the positive strand. Mammalian GPIHBP1 sequences shared $41-96 \%$ identities as compared with 9-32\% sequence identities with other LY6-domain-containing human proteins (LY6-like). The human N-glycosylation site was predominantly conserved among other
\end{abstract}

Electronic supplementary material The online version of this article (doi:10.1007/s13205-011-0026-4) contains supplementary material, which is available to authorized users.

R. S. Holmes - L. A. Cox

Department of Genetics, Texas Biomedical Research Institute, San Antonio, TX, USA

R. S. Holmes · L. A. Cox

Southwest National Primate Research Center,

Texas Biomedical Research Institute, San Antonio, TX, USA

R. S. Holmes

School of Biomolecular and Physical Sciences,

Griffith University, Nathan, Brisbane, QLD, Australia

R. S. Holmes $(\bowtie)$

Department of Genetics, Southwest National Primate Research

Center, Texas Biomedical Research Institute, San Antonio,

TX 78227, USA

e-mail: rholmes@txbiomedgenetics.org mammalian GPIHBP1 proteins except cow, dog and pig. Sequence alignments, key amino acid residues and conserved predicted secondary structures were also examined, including the N-terminal signal peptide, the acidic amino acid sequence region which binds LPL, the glycosylphosphatidylinositol linkage group, the Ly6 domain and the C-terminal $\alpha$-helix. Comparative and phylogenetic studies of mammalian GPIHBP1 suggested that it originated in eutherian mammals from a gene duplication event of an ancestral LY6-like gene and subsequent integration of exon 2, which may have been derived from BCL11A (B-cell CLL/lymphoma $11 \mathrm{~A}$ gene) encoding an extended acidic amino acid sequence.

Keywords Mammals - Amino acid sequence · GPIHBP1 - LY6-like $\cdot$ BCL11A $\cdot$ Evolution ·

Chylomicronemia

\section{Introduction}

Recent studies (Ioka et al. 2003; Beigneux et al. 2007) have shown that a glycosylphosphatidylinositol-anchored highdensity lipoprotein-binding protein 1 (GPIHBP1) of capillary endothelial cells is required for the metabolism of triglyceride-rich lipoproteins in mammalian plasma. This glycoprotein binds lipoprotein lipase (LPL) and apolipoproteins (apoA-V) strongly (Gin et al. 2007, 2011) and may serve as a platform for lipolysis within capillaries, particularly in tissues which show high expression levels for both GPIHBP1 and LPL genes, such as heart, skeletal muscle and adipose tissue (Beigneux et al. 2007; Wion et al. 1987; Havel and Kane 2001; Young et al. 2007). Studies of Gpihbp1 $1^{-} /$Gpihbp1 $^{-}$knock out mice have shown that GPIHBP1-deficiency causes severe hypertriglyceridemia 
with very high plasma triglyceride levels of 2,000$5,000 \mathrm{mg} / \mathrm{dl}$ (Beigneux et al. 2007; Young et al. 2007).

Human clinical studies have also examined loss of function GPIHBP1 mutations leading to familial chylomicronemia. Wang and Hegele (2007) reported two siblings with severe chylomicronemia of 160 patients examined exhibiting chylomicronemia who were homozygous for a GPIHBP1 gene missense mutation (G56R). Franssen et al. (2010) and Olivecrona et al. (2010) have recently identified mutations of conserved cysteines (C65S, C65Y and C68G) in the Ly6 domain of GPIHBP1 in familial chylomicronemia, while Beigneux et al. (2009) have reported a mutant GPIHBP1 (Q115P) which lacked the ability to bind LPL and chylomicrons in a patient with chylomicronemia.

Biochemical studies (Beigneux et al. 2007; Gin et al. 2007, 2011) have suggested that GPIHBP1 is localized on the luminal and abluminal capillary endothelial cell surfaces where it is bound by a glycosylphosphatidylinositol anchor and binds strongly to LPL. GPIHBP1 serves as an LPL transporter from the sub-endothelial spaces to the luminal face of capillaries, enabling lipolysis of circulating triglycerides localized within plasma chylomicrons (Davies et al. 2010; Fisher 2010). Molecular modeling of human GPIHBP1 (Beigneux et al. 2007) and biochemical analyses (Gin et al. 2007) have shown that this protein contains at least four major domains with distinct roles: an $\mathrm{N}$-terminal signal peptide which targets the intracellular trafficking of GPIHBP1 to the cell surface via the endoplasmic reticulum; a very acidic amino acid domain within the GPIHBP1 amino-terminal region may play a role in binding to the positively charged residues of the heparin-binding domain for LPL and apolipoproteins; a cysteine-rich LY6 domain also contributes to LPL binding, as shown by site-directed mutagenesis and human clinical mutation studies (Franssen et al. 2010; Olivecrona et al. 2010); and a C-terminal region which contains a hydrophobic domain which is replaced by a glycosylphosphotidylinositol anchor within the endoplasmic reticulum and which binds GPIHBP1 to the endothelial cell surface (Nosjean et al. 1997; Fisher 2010; Ory 2007). Recently, Gin et al. (2011) have reported several important GPIHBP1-binding properties and have shown specific binding for LPL whereas other related neutral lipases, hepatic lipase (HL) and endothelial lipase (EL), do not bind. In addition, GPIHBP1 also binds APO-A5 strongly whereas another lipid transport protein (APO-A1) does not.

Structures of mammalian GPIHBPI genes have been reported in association with a number of mammalian genome sequencing projects, including human, mouse and rat (Mammalian Genome Project Team 2004; Rat Genome Sequencing Project Consortium 2004), and some mammalian GPIHBP1 cDNA and protein sequences have been described (Ioka et al. 2003; Beigneux et al. 2007; Beigneux et al. 2009a, b). Human, mouse and rat GPIHBP1 genes contain four exons of DNA encoding GPIHBP1 sequences (Thierry-Mieg and Thierry-Mieg 2006).

This paper describes predicted gene structures and amino acid sequences for several mammalian GPIHBPl genes and proteins, and predicted secondary structures for mammalian GPIHBP1 proteins. In addition, we examine the relatedness for mammalian GPIHBP1 with other lymphocyte antigen-6 (Ly6-like) genes and proteins, and describe an hypothesis for the origin of the GPIHBPI gene within eutherian mammals from an ancestral mammalian LY6-like gene and subsequent integration of an exon within the mammalian GPIHBP1 gene encoding the acidic amino acid LPL-binding platform previously described for human and mouse GPIHBP1 (Beigneux et al. 2007; Gin et al. 2007, 2011).

\section{Methods}

Mammalian GPIHBP1 gene and protein identification

Basic Local Alignment Search Tool (BLAST) studies were undertaken using web tools from the National Center for Biotechnology Information (NCBI) (http://blast.ncbi.nlm. nih.gov/Blast.cgi) (Altschul et al. 1997). Protein BLAST analyses used mammalian GPIHBP1 amino acid sequences previously described (Table 1). Non-redundant protein sequence databases for several mammalian genomes were examined using the blastp algorithm, including human (Homo sapiens) (International Human Genome Consortium 2001); chimpanzee (Pan troglodytes) (Chimpanzee Sequencing and Analysis Consortium 2005); orangutan (Pongo abelii) (http://genome.wustl.edu); rhesus monkey (Macaca mulatta) (Rhesus Macaque Genome Sequencing and Analysis Consortium 2007), cow (Bos Taurus) (Bovine Genome Project 2008); horse (Equus caballus) (Horse Genome Project 2008); mouse (Mus musculus) (Mouse Genome Sequencing Consortium 2002); rat (Rattus norvegicus) (Rat Genome Sequencing Project Consortium 2004); opossum (Monodelphis domestica) (Mikkelsen et al. 2007); and platypus (Ornithorhynchus anatinus) (Warren et al. 2008). This procedure produced multiple BLAST 'hits' for each of the protein databases which were individually examined and retained in FASTA format, and a record kept of the sequences for predicted mRNAs and encoded GPIHBP1-like proteins. These records were derived from annotated genomic sequences using the gene prediction method: GNOMON and predicted sequences with high similarity scores for human GPIHBP1. Predicted GPIHBP1like protein sequences were obtained in each case and subjected to analyses of predicted protein and gene structures.

Blast-Like Alignment Tool (BLAT) analyses were subsequently undertaken for each of the predicted GPIHBP1 


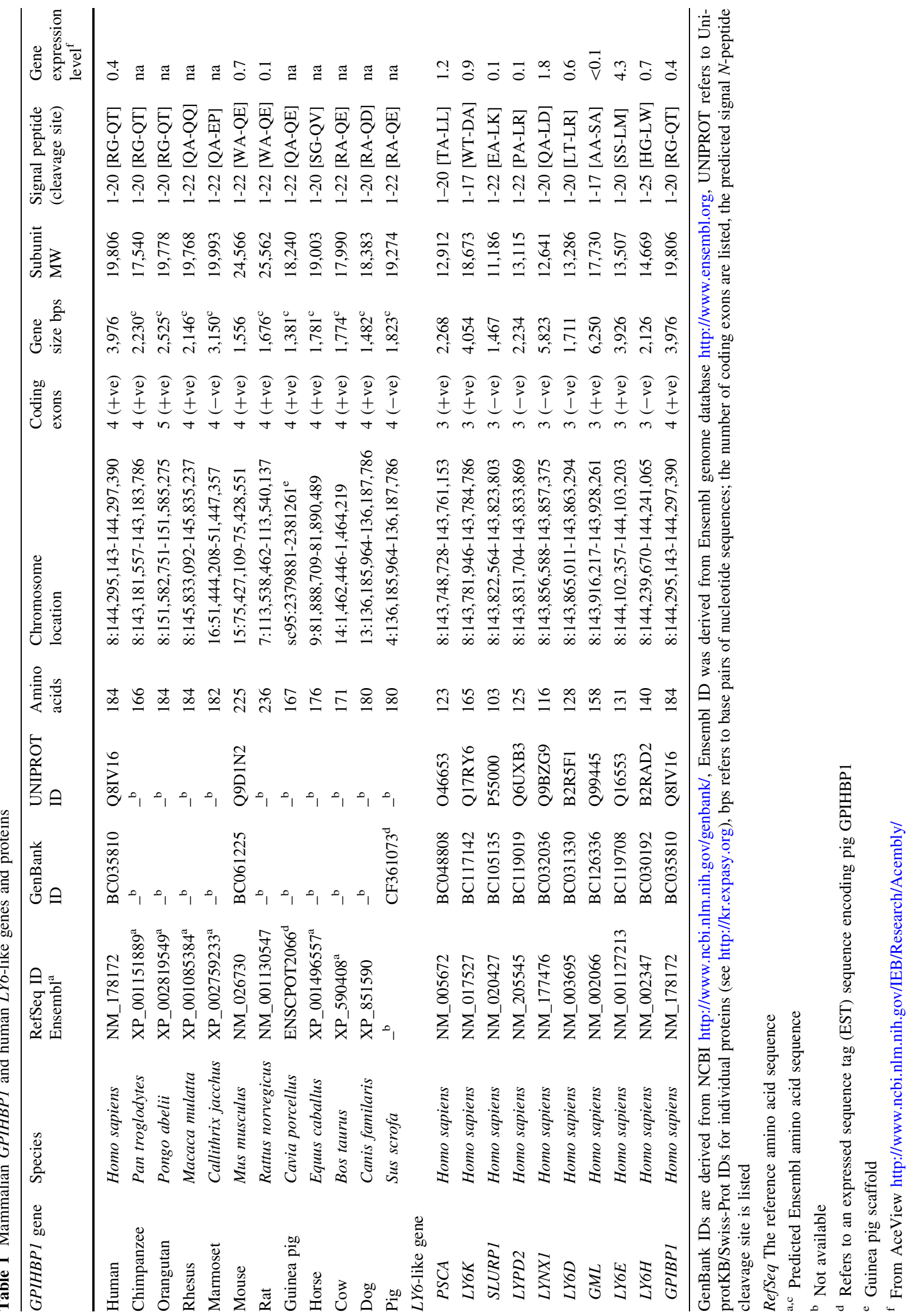


amino acid sequences using the University of California Santa Cruz (UCSC) Genome Browser [http://genome.ucsc. edu/cgi-bin/hgBlat] (Kent et al. 2003) with the default settings to obtain the predicted locations for each of the mammalian GPIHBPI genes, including predicted exon boundary locations and gene sizes. BLAT analyses were similarly undertaken for other mammalian LY6-like and vertebrate BCL11A-like (encoding B-cell CLL/lymphoma 11A) genes and proteins using previously reported sequences for LY6D, LY6E, LY6H, LY6K, LY6NX1, PSCA, SLURP1, GML, LY6D2 and BCL11A in each case (Tables 1, 2, 3). Structures for human, mouse and rat GPIHBP1 genes and encoded proteins were obtained using the AceView website Thierry-Mieg and Thierry-Mieg 2006) (http://www.ncbi.nlm.nih.gov/IEB/Research/Acembly/index. html?human).

Predicted structures, properties and alignments of mammalian GPIHBP1 and human LY6-like sequences

Predicted secondary structures for human and other mammalian GPIHBP1 proteins were obtained using the PSIPRED v2.5 website tools [http://bioinf.cs.ucl.ac.uk/psipred/ psiform.html] (McGuffin et al. 2000). Other web tools were used to predict the presence and locations of the following for each of the mammalian GPIHBP1 sequences: SignalP 3.0 for signal peptide cleavage sites (http://www.cbs. dtu.dk/services/SignalP/) (Emmanuelsson et al. 2007); NetNGlyc 1.0 for potential N-glycosylation sites (http:// www.cbs.dtu.dk/services/NetNGlyc/); and big-PI Predictor for the glycosylphosphatidylinositol linkage groupanchored sites (http://mendel.imp.ac.at/sat/gpi/gpi_server. html) (Eisenhaber et al. 1998). The reported tertiary structure for human CD59 (membrane-bound glycoprotein) (Leath et al. 2007) served as the reference for the predicted human, rat, pig and guinea pig GPIHBP1 tertiary structures, with modeling ranges of residues 62-138, 69-146, 65-141 and 61-139, respectively. Alignments of mammalian GPIHBP1 sequences with human LY6D, LY6E, LY6H, LY6K, LYNX1 and LYPD2 lymphocyte antigen-6related proteins or with vertebrate B-cell CLL/lymphoma 11A (BCL11A) sequences were assembled using the ClustalW2 multiple sequence alignment program (Larkin et al. 2007) (http://www.ebi.ac.uk/Tools/clustalw2/index.html).

Comparative bioinformatics of mammalian GPIHBP1, vertebrate $L Y 6$-like and vertebrate $B C L 11 A$ genes and proteins

The UCSC Genome Browser (http://genome.ucsc.edu) (Kent et al. 2003) was used to examine comparative structures for mammalian GPIHBP1 (Table 1), vertebrate
LY6-like (lymphocyte antigen-6 complex; Tables 1,2) and vertebrate BCL11A (B-cell CLL/lymphoma 11A) (Table 3) genes and proteins. We also used the UCSC Genome Browser Comparative Genomics track that shows alignments of up to 28 vertebrate species and evolutionary conservation of GPIHBPl gene sequences. Species aligned for this study included 4 primates, 6 non-primate eutherian mammals (e.g., mouse, rat), a marsupial (opossum), a monotreme (platypus) and bird species (chicken). Conservation measures were based on conserved sequences across all of these species in the alignments which included the $5^{\prime}$ flanking, 5'-untranslated and coding regions of the GPIHBPl gene.

BLAT analyses were subsequently undertaken using the nucleotide sequence for exon 2 of human GPIHBP1 using the UCSC Genome Browser [http://genome.ucsc.edu/cgi-bin/ hgBlat] (Kent et al. 2003) to identify homologs for this exon in the human genome.

Phylogenetic studies and sequence divergence

Alignments of mammalian GPIHBP1 and vertebrate LY6like protein sequences were assembled using BioEdit v.5.0.1 and the default settings (Hall 1999). Alignment ambiguous regions, including the acidic amino acid region of GPIHBP1, were excluded prior to phylogenetic analysis yielding alignments of 60 residues for comparisons of sequences with the zebrafish (Danio rerio) LY6-like (LYPD6) sequence (Tables 1, 2). Evolutionary distances were calculated using the Kimura option (Kimura 1983) in TREECON (Van De Peer and de Wachter 1994). Phylogenetic trees were constructed from evolutionary distances using the neighbor-joining method (Saitou and Nei 1987) and rooted with the zebrafish LYPD6 sequence. Tree topology was reexamined by the bootstrap method (100 bootstraps were applied) of resampling and only values that were highly significant $(\geq 90)$ are shown (Felsenstein 1985).

\section{Results and discussion}

Alignments of mammalian GPIHBP1 amino acid sequences with human LY6-related antigen sequences

The deduced amino acid sequences for orangutan (Pongo abelii), rhesus monkey (Macaca mulatta), marmoset (Callithrix jacchus), horse (Equus caballus), cow (Bos taurus) and rat (Rattus norvegicus) GPIHBP1 are shown in Fig. 1 together with previously reported sequences for human and mouse GPIHBP1 (Beigneux et al. 2007; Gin et al. 2007). In addition, amino acid sequences for several LY6-related lymphocyte antigen sequences are also 


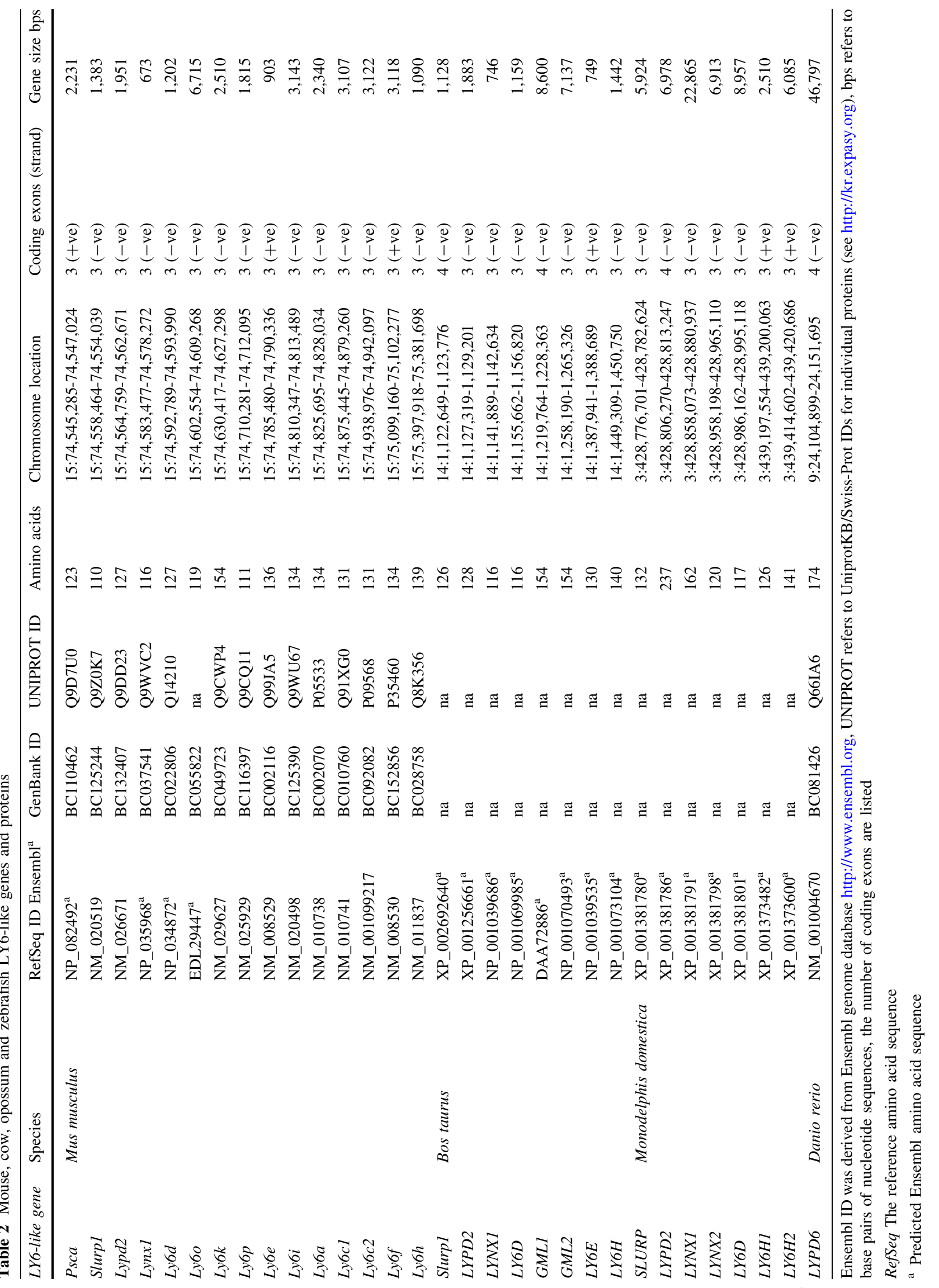


Table 3 Vertebrate BCL11A genes and proteins

\begin{tabular}{|c|c|c|c|c|c|c|c|c|}
\hline $\begin{array}{l}\text { Mammalian } \\
\text { BCL11A } \\
\text { Gene }\end{array}$ & Species & $\begin{array}{l}\text { RefSeq ID } \\
\text { Ensembl }^{\mathrm{a}}\end{array}$ & $\begin{array}{l}\text { GenBank } \\
\text { ID }\end{array}$ & $\begin{array}{l}\text { UNIPROT } \\
\text { ID }\end{array}$ & $\begin{array}{l}\text { Amino } \\
\text { acids }\end{array}$ & $\begin{array}{l}\text { Chromosome } \\
\text { location }\end{array}$ & $\begin{array}{l}\text { Coding exons } \\
\text { (strand) }\end{array}$ & $\begin{array}{l}\text { Gene } \\
\text { size bps }\end{array}$ \\
\hline Human & Homo sapiens & NM_018014 & ВC021098 & Q9H165 & 773 & $2: 60,678,303-60,780,633$ & $5(-v e)$ & 102,331 \\
\hline Orangutan & Pongo abelii & XP_002812058 $8^{\mathrm{a}}$ & na & na & 808 & $2: 50,366,387-50,465,154$ & $6(+v e)$ & 98,768 \\
\hline Marmoset & Callithrix jacchus & XP_002757779 $9^{\mathrm{a}}$ & na & na & 808 & $14: 46,690,157-46,792,384$ & $6(+v e)$ & 102,228 \\
\hline Mouse & Mus musculus & NM_016707 & ВC010585 & Q9QYE3 & 773 & $11: 23,978,391-24,072,787$ & $5(+v e)$ & 94,397 \\
\hline Pig & Sus scrofa & XP_003125157 $7^{\mathrm{a}}$ & AK231444 & na & 773 & $3: 74,933,998-75,031,771$ & $5(+v e)$ & 97,774 \\
\hline Rabbit & Oryctolagus cuniculus & XP_002709742 & na & na & 821 & $2: 125,646,621-125,730,521$ & $4(+v e)$ & 83,901 \\
\hline Dog & Canis familiaris & $\mathrm{XP} \_865536^{\mathrm{a}}$ & na & na & 773 & $10: 63,737,516-63,836,852$ & $5(-\mathrm{ve})$ & 99,337 \\
\hline Chicken & Gallus gallus & NM_001031031 & AJ551441 & Q5F459 & 796 & $3: 1,829,458-1,877,784$ & $3(-\mathrm{ve})$ & 48,237 \\
\hline Lizard & Anolis carolinensis & XP_003216184 ${ }^{\mathrm{a}}$ & na & na & 796 & $276: 252,030-507,710^{\mathrm{b}}$ & $3(+v e)$ & 255,681 \\
\hline Zebrafish & Danio rerio & NP_001035481 ${ }^{\mathrm{a}}$ & na & A2BE84 & 829 & $13: 26,077,202-26,148,770$ & $3(+v e)$ & 71,569 \\
\hline
\end{tabular}

$B C L 11 A$ refers to the gene encoding vertebrate B-cell CLL/lymphoma $11 \mathrm{~A}$ sequences

Ensemble ID was derived from Ensembl genome database http://www.ensembl.org; UNIPROT refers to UniprotKB/Swiss-Prot IDs for individual proteins (see http://kr.expasy.org); bps refers to base pairs of nucleotide sequences; the number of coding exons are listed

RefSeq The reference amino acid sequence

${ }^{a}$ Predicted Ensembl amino acid sequence

${ }^{\mathrm{b}}$ Refers to scaffold ID

aligned with the mammalian GPIHBP1 sequences, including human LY6D (Brakenoff et al. 1995), LY6E (Capone et al. 1996), LYPD2 (Clark et al. 2003), LY6H (Horie et al. 1998), LY6K (Ishikawa et al. 2007) and LYNX1 (Mammalian Genome Project Team 2004) (Table 1). Alignments of human and other mammalian GPIHBP1 sequences examined showed identities between 46 and $96 \%$, suggesting that these are the products of the same gene family, whereas comparisons of sequence identities of mammalian GPIHBP1 proteins with human LY6-like lymphocyte antigen sequences exhibited low levels of sequence identities (9-32\%), indicating that these are the members of distinct protein families (Table 4).

The amino acid sequences for most of the mammalian GPIHBP1 proteins contained 167-184 residues whereas mouse and rat GPIHBP1 contained 225 and 236 amino acids, respectively, with the latter having extended C-terminal sequences (Fig. 1). Previous biochemical and genetic analyses of human and mouse GPIHBP1 (Beigneux et al. 2007; Gin et al. 2007, 2011) have enabled predictions of key residues for these mammalian GPIHBP1 proteins (sequence numbers refer to human GPIHBP1). These included the $\mathrm{N}$-terminus signal peptide (residues 1-20) which participates in the trafficking of GPIHBP1 via the endoplasmic reticulum; two acidic amino acid clusters (residues 25-32 and 41-50) which may contribute to LPL binding within a basic amino acid LPL heparin-binding site region (Sendak and Bensadoun 1998); a conserved Gly56 with an unknown function (Gin et al. 2007); a predominantly conserved $\mathrm{N}$-glycosylation site (Asn78-Leu79-Thr80) which is critical for the movement of GPIHBP1 onto the cell surface (Beigneux et al. 2008); a urokinase plasminogen activator receptor (UPAR)-lymphocyte antigen-6 (LY6) domain which contains 10 conserved cysteine residues (Cys65, Cys68, Cys77, Cys83, Cys89, Cys110, Cys114, Cys130, Cys131 and Cys136) and forms five disulfide bridges within this domain; Gln115 which plays a role in LPL binding to GPIHBP1 (Franssen et al. 2010); and a hydrophobic C-terminal helix domain (residues 160-178) which is replaced by a glycosylphosphatidylinositol anchor (to Gly159) and is responsible for linking GPIHBP1 to the endothelial cell surface (Nosjean et al. 1997; Davies et al. 2010; Fisher 2010). These residues and predicted properties were conserved for all of the mammalian GPIHBP1 sequences examined (Fig. 1) with the exception of the cow GPIHBP1 sequence, which lacked a predicted N-glycosylation site (Beigneux et al. 2008). Predicted N-glycosylation site(s) were also absent in guinea pig, dog and pig GPIHBP1 sequences; whereas human and orangutan GPIHBP1 sequences exhibited two predicted $\mathrm{N}$-glycosylation sites (Asn78-Leu79-Thr80 and Asn82-Cys83-Ser84) (Table 5) although experimental evidence for in vivo $\mathrm{N}$-glycosylation is only available for the first site (Beigneux et al. 2008).

The human LY6-like sequences examined shared several of the mammalian GPIHBP1 domain regions, including the $\mathrm{N}$-signal peptide region (sequence numbers refer to human LY6D) (residues 1-20); the UPAR-LY6 domain with 10 conserved cysteine residues (Cys23, Cys26, Cys32, Cys38, Cys45, Cys63, Cys67, Cys86, Cys87 and Cys92) forming five disulfide bonds previously reported for 


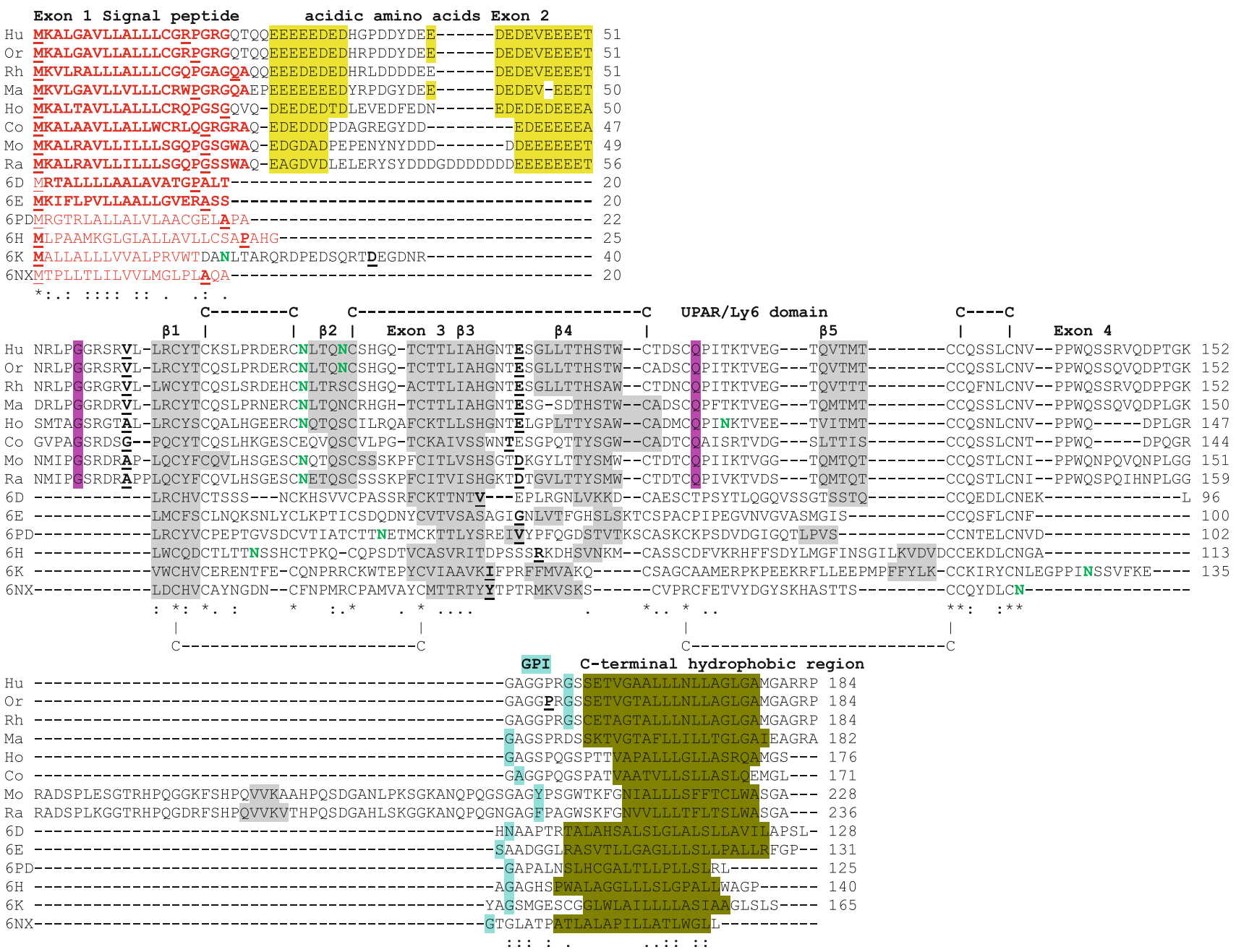

Fig. 1 Amino acid sequence alignments for mammalian GPIHBP1 and human LY6-like sequences. See Table 1 for sources of glycosylphosphatidylinositol-anchored high-density lipoprotein-binding protein 1 (GPIHBP1) and human LY6-like sequences: GPIHBP1- $\mathrm{Hu}$ human, $\mathrm{Or}$ orangutan, $\mathrm{R} h$ rhesus, $\mathrm{Ma}$ marmoset, $\mathrm{Ho}$ horse, Co cow, Mo mouse, Ra rat; Human LY6-like: 6D-LY6D; 6E-LY6E; 6D2-LY6D2; 6H-LY6H; 6K-LY6K; 6NX-LY6NX. Asterisks show identical residues for proteins, colon similar alternate residues, dot dissimilar alternate residues. Residues predicted for involvement in $\mathrm{N}$-signal peptide formation are shown in red, $\mathrm{N}$-glycosylated and potential $\mathrm{N}$-glycosylated Asn sites are in green

LY6-like proteins (Fry et al. 2003; Leath et al. 2007), and the hydrophobic C-terminal helix domain (residues 104-125) which is replaced by a glycosylphosphatidylinositol anchor (predicted to be bound to Asn98). These LY6-like sequences, however, lacked the N-terminal acidic amino acid domain and contained fewer amino acids in the protein region surrounding the UPAR-Ly6 domain (residues 21-96). These sequences also lacked the predominantly conserved $\mathrm{N}$-glycosylation site observed for mammalian GPIHBP1 proteins but contained amidation sites for attaching the glycosylphosphatidylinositol anchor in each case. bold, key GPIHBP1 functional residues 56Gly and 114Gln are in shaded pink, predicted disulfide bond Cys residues are shown; $\alpha$-helices predicted for GPIHBP1 are in shaded yellow, $\beta$-sheets $(\beta 1-\beta 5)$ predicted for mammalian GPIHBP1 or for human LY6-like sequences are in shaded grey, bold underlined font shows residues corresponding to known or predicted exon start sites. Exon numbers refer to GPIHBP1 human gene exons, the sequences for the UPAR/ Ly6 domain are shown, C-terminal hydrophobic amino acid segment is shown as shaded green, known (human and mouse) or predicted mammalian GPIHBP1 and human LY6-like GPI-binding sites are shown in shaded blue

\section{Predicted structures for mammalian GPIHBP1 proteins}

Predicted secondary structures for mammalian GPIHBP1 sequences were compared with those predicted for human lymphocyte antigen-6-like proteins (Fig. 1). $\alpha$-Helix and $\beta$-sheet structures for these sequences were similar for several regions with the human LY6-like secondary structures, including the N-terminal signal peptide which contained an extended helical structure; the UPAR-LY6 domain which contained four or five $\beta$-sheet structures (designated as $\beta 1-\beta 5$ ) within the region for five disulfide bonds; and the $\mathrm{C}$-terminal hydrophobic region, which is 


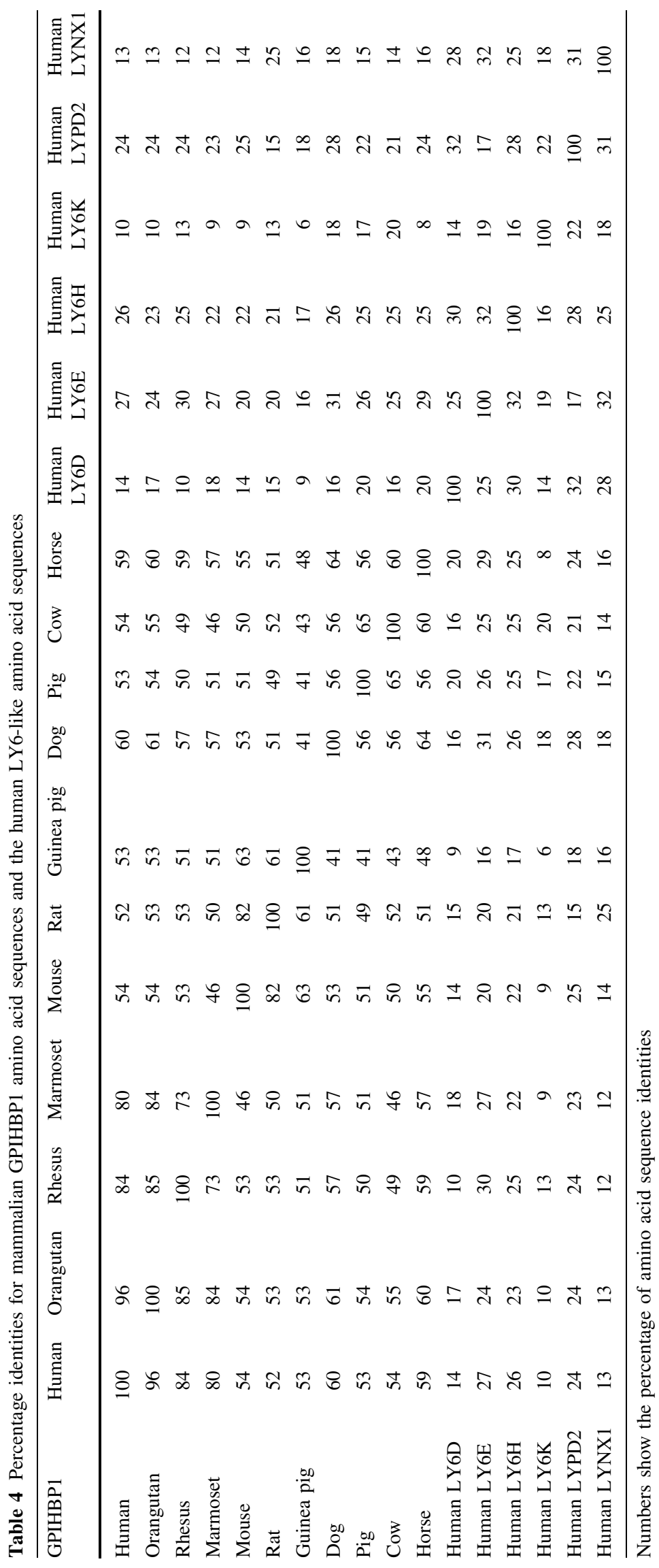


Table 5 Predicted N-glycosylation sites for mammalian GPIHBP1 sequences

\begin{tabular}{|c|c|c|c|c|c|c|c|c|c|c|}
\hline $\begin{array}{l}\text { Mammalian } \\
\text { GPIHBP1 }\end{array}$ & Species & Site 1 & $\begin{array}{l}\text { Site } 1 \\
\text { potential }\end{array}$ & Site 2 & $\begin{array}{l}\text { Site } 2 \\
\text { potential }\end{array}$ & Site 3 & $\begin{array}{l}\text { Site } 3 \\
\text { potential }\end{array}$ & Site 4 & $\begin{array}{l}\text { Site } 4 \\
\text { potential }\end{array}$ & $\begin{array}{l}\text { No. of } \\
\text { potential } \\
\text { sites }\end{array}$ \\
\hline Human & Homo sapiens & 78NLTQ & 0.76 & 82NCSH & 0.61 & & & & & 2 \\
\hline Orangutan & Pongo abelii & 78NLTQ & 0.76 & 82NCSH & 0.61 & & & & & 2 \\
\hline Rhesus & Macaca mulatta & 78NLTR & 0.69 & & & & & & & 1 \\
\hline Marmoset & Callithrix jacchus & 77NLTQ & 0.80 & & & & & & & 1 \\
\hline Mouse & Mus musculus & 76NQTQ & 0.53 & & & & & & & 1 \\
\hline Rat & Rattus norvegicus & 84NETQ & 0.55 & & & & & & & 1 \\
\hline Guinea Pig & Cavia porcellus & 76NQTE & NP & & & & & 150NGTT & NP & 0 \\
\hline Horse & Equus caballus & 77NQTQ & 0.68 & & & 118NKTV & 0.70 & & & 2 \\
\hline Cow & Bos taurus & & & & & & & & & 0 \\
\hline Dog & Canis familaris & & & & & & & & & 0 \\
\hline Pig & Sus scrofa & & & & & & & & & 0 \\
\hline
\end{tabular}

Predicted N-glycosylation sites were identified using NetNGlyc 1.0 web tools (http://www.cbs.dtu.dk/services/NetNGlyc/) ${ }^{32}$, potential for $\mathrm{N}$-glycosylation sites was determined by the web tools (maximum level of 1)

Bold values designate high probability of forming an $\mathrm{N}$-glycosylation site

$N$ Asparagine, $L$ leucine, $Q$ glutamine, $T$ threonine, $C$ cysteine, $R$ arginine, $E$ glutamate, $H$ histidine, $V$ valine, $N P$ no prediction for an $\mathrm{N}$-glycosylation site

removed following GPI-attachment within the endoplasmic reticulum. The distinctive secondary structures observed for mammalian GPIHBP1 sequences were two acidic amino acid $\alpha$-helical regions which were notably absent in the LY6-like predicted secondary structures.

Tertiary structures for the members of the LY6 protein family has been reported previously which are characterized by an amino acid motif containing eight or ten cysteine residues arranged in consistent spacing patterns forming four or five disulfide bonds and a three-finger motif which comprised $\beta$-pleated sheets predominantly. The predicted secondary structures observed for the human LY6-like proteins (LY6D, LY6E, LY6PD, LY6H, LY6K and LY6NX1) and the mammalian GPIHBP1 protein sequences examined are consistent with the presence of this LY6 protein family motif within these proteins (Fig. 1). Figure 2 describes predicted tertiary structures for human, rat, pig (Sus scrofa) and guinea pig (Cavia porcellus) GPIHBP1 protein sequences and shows significant similarities to the UPAR-LY6 domain reported for the human CD59 antigen (membrane-bound glycoprotein) (Leath et al. 2007). Five anti-parallel $\beta$-sheets are readily apparent in each case, which is consistent with the predictions observed for the human and rat GPIHBP1 proteins shown in the amino acid sequence alignments in Fig. 1. This suggests that the UPAR-LY6 domain secondary and tertiary structures are shared among all GPIHBP1 proteins examined as well as the human LY6-like proteins examined.
The overall structure for mammalian GPIHBP1 may then comprise the two $\alpha$-helices of acidic amino acids (which bind LPL to GPIHBP1) and the three-fingered $\beta$-sheet motif which is covalently linked to the plasma membrane by a glycosylphosphatidylinositol anchor. Recent studies have shown that both motifs are essential for LPL binding and transport and for GPIHBP1 function (Beigneux et al. 2009a, b; Gin et al. 2011).

\section{Comparative human GPIHBP1 tissue expression}

Beigneux et al. (2009b) have previously examined Gpihbpl tissue expression in mouse tissues and reported high levels of expression in heart and adipose tissue, which corresponds with the major distribution for LPL in the body and supports the key role played by this enzyme in lipid metabolism, especially in heart and adipose tissue (Wion et al. 1987; Havel and Kane 2001). Overall, human GPIHBP1, and mouse and rat Gpihbpl genes were moderately expressed in comparison with the other lymphocyte antigen-like genes being $0.1-0.7$ times the average level of gene expression in comparison with human LY6E and LYNXI genes, which showed expression levels of 4.3 and 1.8 times the average gene, respectively (Table 1). This may reflect a more restricted GPIHBPI cellular expression as compared with LY6-like genes and/or a more specialized role of GPIHBP1 is being responsible for LPL binding in heart and adipose tissue as compared with the broader and more widely distributed functions of LY6-like proteins as lymphocyte antigens throughout the body. 
Fig. 2 Predicted tertiary structures for the UPAR/Ly6 domain for human, rat, guinea pig and pig GPIHBP1. Predicted GPIHBP1 tertiary structures were obtained using SWISS MODEL methods; the rainbow color code describes the tertiary structures from the $\mathrm{N}-$ (blue) to C-termini (red color) for human, rat, guinea pig and pig GPIHBP1 UPAR/Ly6 domains; arrows indicate the directions for $\beta$-sheets
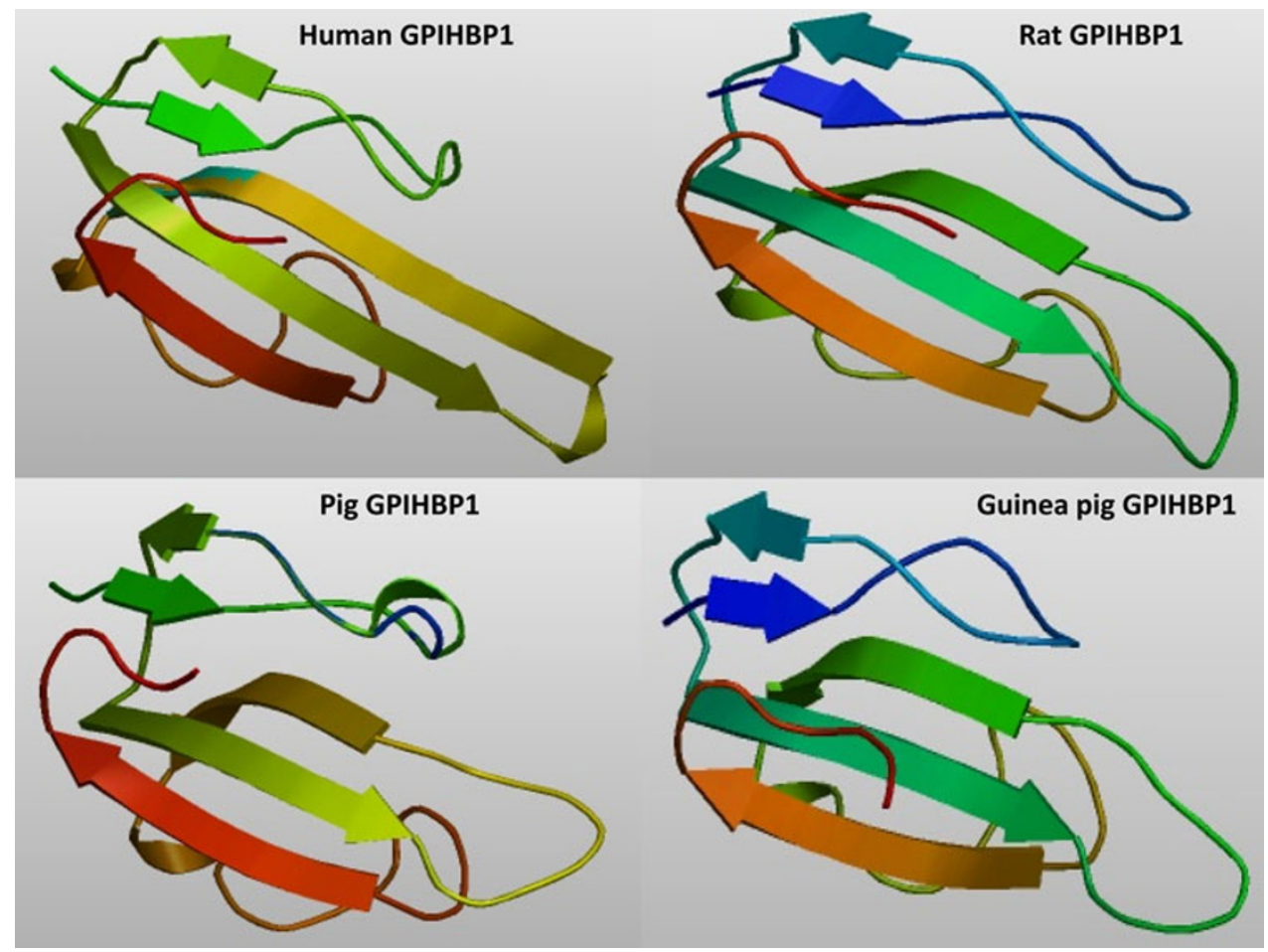

Gene locations and exonic structures for mammalian GPIHBP1 genes and human LY6-like genes

Table 1 summarizes the predicted locations for mammalian GPIHBPl genes and human LY6-like genes based on BLAT interrogations of several mammalian genomes using the reported sequences for human and mouse (Beigneux et al. 2007; Gin et al. 2007, 2011) and the predicted sequences for the other mammalian GPIHBP1 proteins and the UCSC Genome Browser (Kent et al. 2003). Table 2 also presents the predicted locations and other features for mouse, cow and opossum LY6-like genes and proteins. The mammalian GPIHBP1 genes were predominantly transcribed on the positive strand, with the exception of the marmoset and pig genes which were transcribed on the negative strand. Figure 1 summarizes the predicted exonic start sites for mammalian GPIHBP1 genes with most having 4 coding exons in identical or similar positions to those predicted for the human GPIHBPl gene, with the exception of the orangutan GPIHBPl gene, which contained an additional exon within the encoding region for the C-terminal sequence. In contrast, the human, mouse, cow and opossum LY6-like genes examined contained only 3 coding exons encoded on either the positive or negative strands. These results are indicative of structural similarities between the mammalian GPIHBPI and LY6-like genes but with the GPIHBPI genes possessing an additional exon (exon 2) in each case.
Figure 3 summarizes the comparative locations of human, rhesus monkey, mouse, cow and opossum LY6-like genes within respective gene clusters. Nine human and rhesus LY6-like and the related GPIHBPl genes, for example, were localized within 535 or $618 \mathrm{~kb}$ gene clusters, respectively, on human and rhesus chromosome 8 whereas 15 mouse Ly6-like genes and the Gpihbpl gene were colocalized within a $883-\mathrm{kb}$ gene cluster on mouse chromosome 15. Cow and opossum (Monodelphis domestica-a marsupial mammal) LY6-like genes were also similarly located within respective gene clusters on chromosomes 14 and 3, respectively, although in each case, there were fewer LY6-like genes identified in comparison with human and rhesus genomes, and particularly the mouse genome. Of special interest to this current study, however, is the absence of an identified opossum GPIHBPl-like gene and the presence of two predicted opossum $L Y 6 H$-like genes on chromosome 3 of the opossum genome. For each of the mammalian genomes examined (human, rhesus monkey, mouse, cow and opossum), there were similarities in LY6-like gene order: LYPD2-LYNX1-LY6D-LY6E-LY6H$G P I H B P 1$, but with $G P I H B P 1$ being undetected in the case of the opossum genome.

Figure 4 shows the predicted structures of mRNAs for human, mouse and rat GPIHBP1 transcripts (Thierry-Mieg and Thierry-Mieg 2006) which were 2.3-3.1 kbs in length with three introns and four exons present and in each case, an extended $3^{\prime}$-untranslated region (UTR) was observed. 
Fig. 3 Comparative gene clusters for mammalian LY6like genes. LY6-like gene clusters are identified with the size of the cluster (in kilobases) in each case. Individual LY6like genes were identified and positioned using data summarized in Tables 1 and 2 . The arrow shows the direction for transcription: right arrow the positive strand; left arrow the negative strand. Note the absence of an identified GPIHBP1 gene on the opossum genome

Fig. 4 Gene and mRNA structures for the human, mouse and rat GPIHBP1 genes. Derived from the AceView website http://www.ncbi.nlm.nih.gov/ IEB/Research/Acembly/ (Thierry-Mieg and Thierry-Mieg 2006); mature isoform variants (a) are shown with capped $5^{\prime}$ - and $3^{\prime}$-ends for the predicted mRNA sequences. NM refers to the NCBI reference sequence.

Exons are in shaded pink; untranslated $5^{\prime}$ - and $3^{\prime}$ sequences are in open pink, introns are represented as pink lines joining exons, the directions for transcription are shown as $5^{\prime} \rightarrow 3^{\prime}$, sizes of mRNA sequences are shown in kilobases $(\mathrm{kb})$

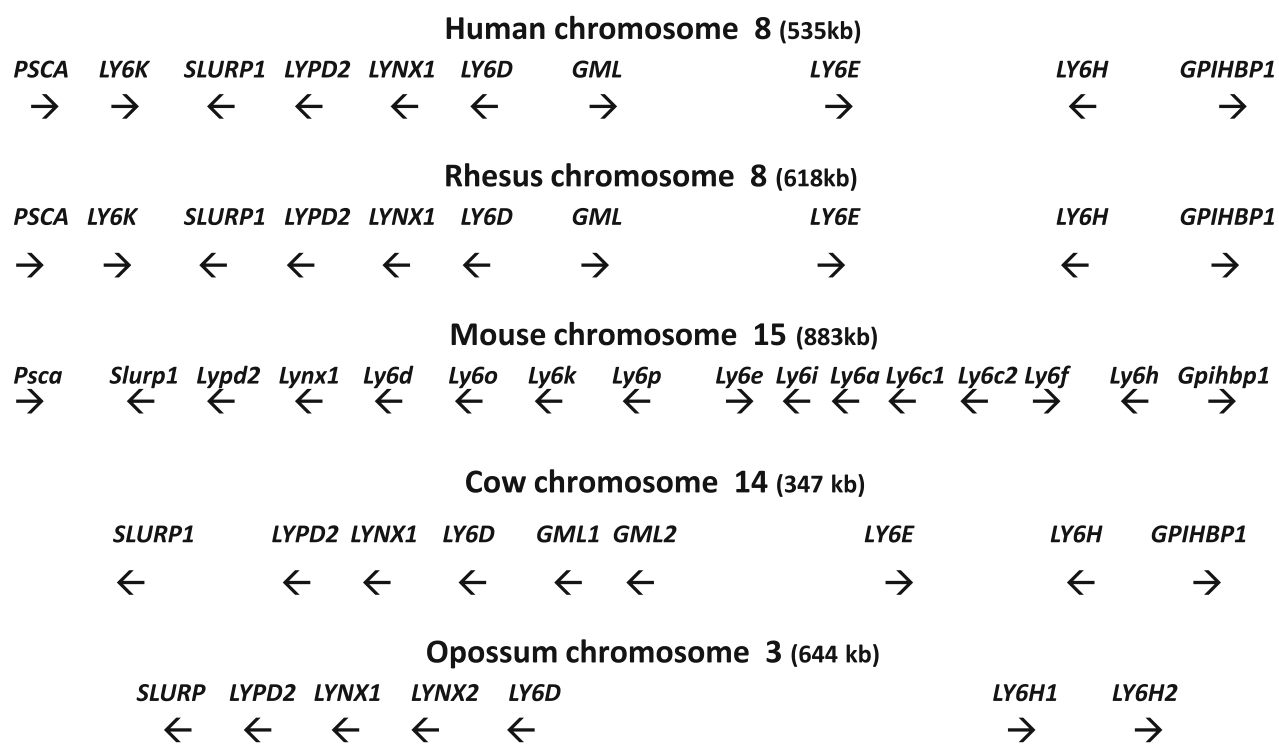

Human GPIHBP1

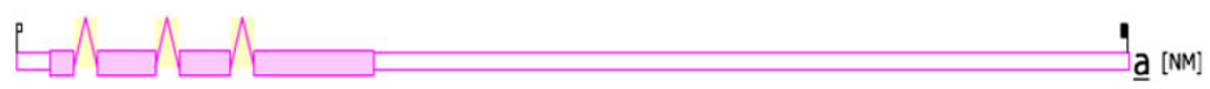

$0 \quad 100200 \mathrm{bp}$

Mouse GPIHBP1
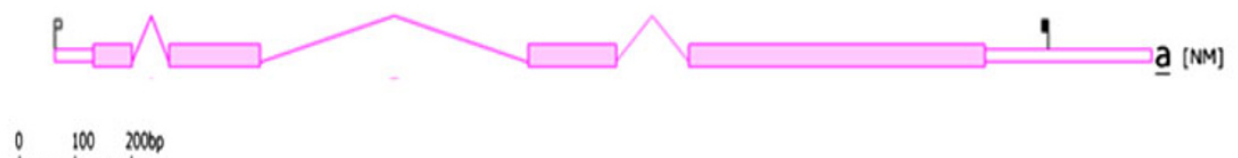

Rat GPIHBP1

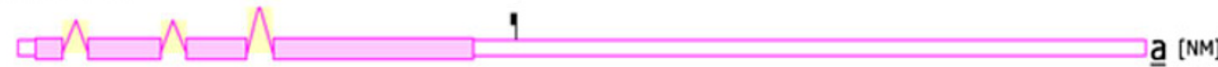

$0 \quad 100200 \mathrm{bp}$

Encoded on the plus strand $5^{\prime} \rightarrow 3^{\prime}$
Evolutionary appearance of the GPIHBPl gene in mammalian genomes

Figure 5 shows a UCSC Genome Browser Comparative Genomics track that shows evolutionary conservation and alignments of the nucleotide sequences for the human GPIHBPl gene, including the 5'-flanking, 5'-untranslated, intronic, exonic and $3^{\prime}$-untranslated regions of this gene, with the corresponding sequences for 12 mammalian and bird genomes, including 4 primates (e.g., rhesus), 6 nonprimate eutherian mammals (e.g., mouse, rat), a marsupial (opossum), a monotreme (platypus) and a bird species (chicken). Extensive conservation was observed among these GPIHBPI genomic sequences for the eutherian mammalian genomes, particularly for the primate species but also for the exonic and $5^{\prime}$-flanking regions for all eutherian genomes examined. An examination of nonsynonymous (ns) single nucleotide polymorphisms (SNPs) within the human genome supported this conclusion of GPIHBP1 conservation with this gene containing only a single ns-SNP within exon 1 . In contrast with the eutherian mammalian genomes examined, the opossum (marsupial mammal) genome lacked conserved sequences within the 5 '-flanking and exon 1 and 2 regions, but showed some genomic sequence conservation within the exon 3 and exon 4 regions. The platypus (monotreme mammal) exhibited conserved GPIHBPl gene sequences within the 5 -flanking and exon 3 and 4 regions but showed no conservation of other sections of this gene, and lacked exon 1 and 2 conserved sequences. In addition, the chicken (bird) genomic sequence showed no significant conservation of any region of the GPIHBPl gene, which is consistent with BLAT 


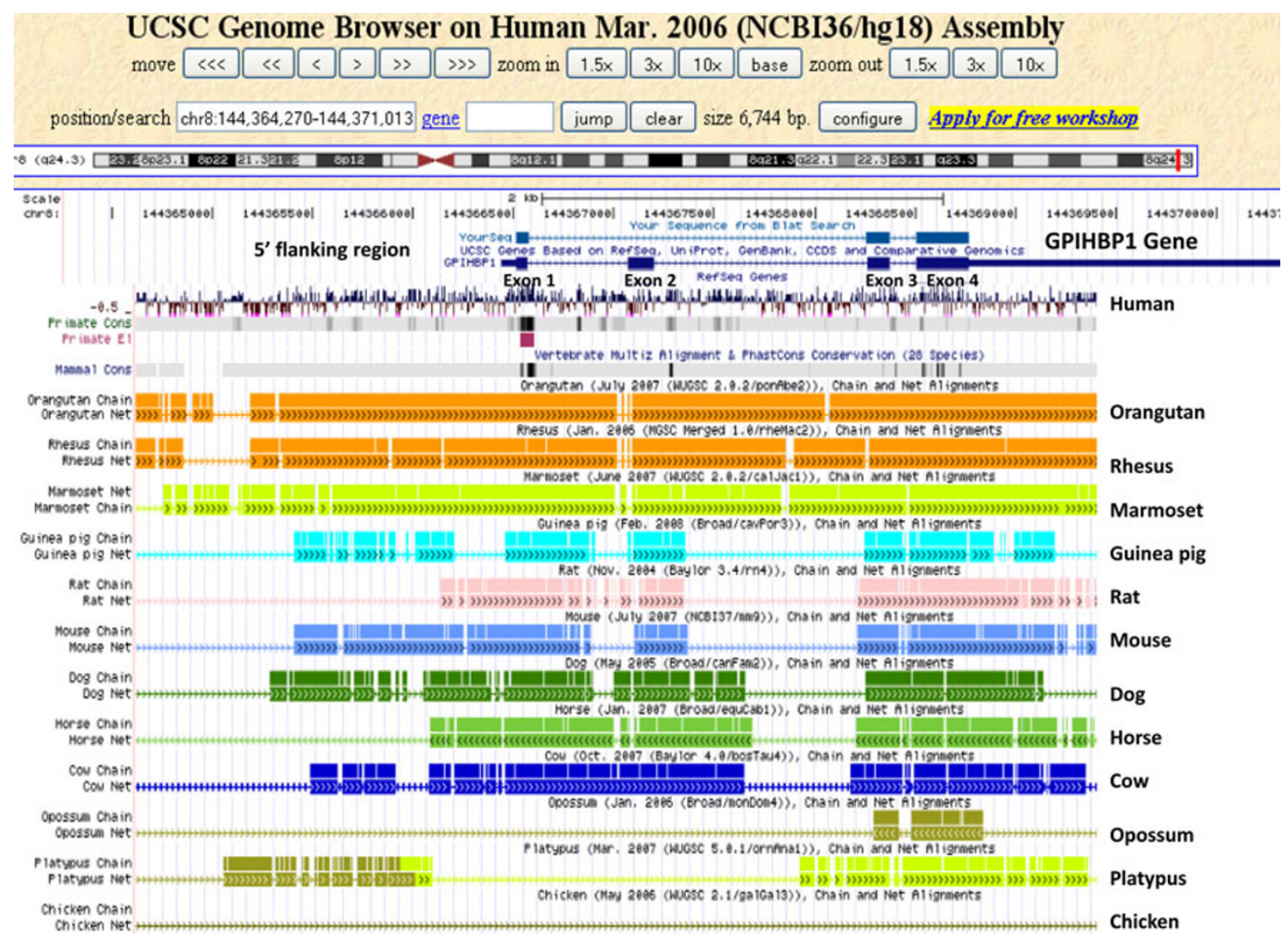

Fig. 5 Comparative sequences for mammalian $5^{\prime}$-flanking, $5^{\prime}$ untranslated and coding regions for the GPIHBP1 genes. Derived from the UCSC Genome Browser using the Comparative Genomics track to examine alignments and evolutionary conservation of GPIHBP1 gene sequences; genomic sequences aligned for this study included primate (human, orangutan, rhesus and marmoset), nonprimate eutherian mammal (mouse, rat, guinea pig, dog, horse and cow), a marsupial (opossum), a monotreme (platypus) and bird species (chicken); conservation measures were based on conserved sequences across all of these species in the alignments which included the $5^{\prime}$-flanking, $5^{\prime}$-untranslated, exons, introns and $3^{\prime}$-untranslated regions for the GPIHBP1 gene; regions of sequence identity are shaded in different colors for different species

were further subdivided into groups, including PSCA, LYNX1, LY6D, LY6H, SLURP1, LYPD2, LY6E, LY6K, GML and a group of mouse Ly6-like sequences (designated as Ly6a, Ly6c1, Ly6c2, Ly6f and Ly6i). These groups were significantly different from each other (with bootstrap values >90) and have apparently evolved as distinct genes and proteins during mammalian evolution. Moreover, it is apparent that GPIHBP1 is a distinct but related $L Y 6$-like gene which has appeared early in eutherian mammalian evolution.

Hypothesis: proposed mechanism for the evolutionary appearance of GPIHBPI in eutherian mammals

A search was undertaken for a potential gene 'donor' for the exon encoding the acidic amino acid motif contained within the mammalian GPIHBP1 gene using BLAT to interrogate the human genome with the known nucleotide sequence for exon 2 of the human GPIHBP1 gene (Kent et al. 2003). A region of the human $B C L 11 A$ gene (encoding acidic residues sequence. In addition, the mammalian LY6-like sequences 
Fig. 6 Phylogenetic tree of mammalian GPIHBP1 and other LY6-like sequences. The tree is labeled with the gene name and the name of the animal and is 'rooted' with the zebrafish (Danio rerio) LY6PD sequence. Note the major cluster for the mammalian GPIHBP1 sequences and several major groups of the other LY6-like sequences: LYNX1, LY6D, LY6H, SLURP1, LYPD2, PSCA, LT6E, LY6K, and GML. A genetic distance scale is shown (\% amino acid substitutions). The number of times a clade (sequences common to a node or branch) occurred in the bootstrap replicates are shown. Only replicate values of 90 or more which are highly significant are shown with 100 bootstrap replicates performed in each case
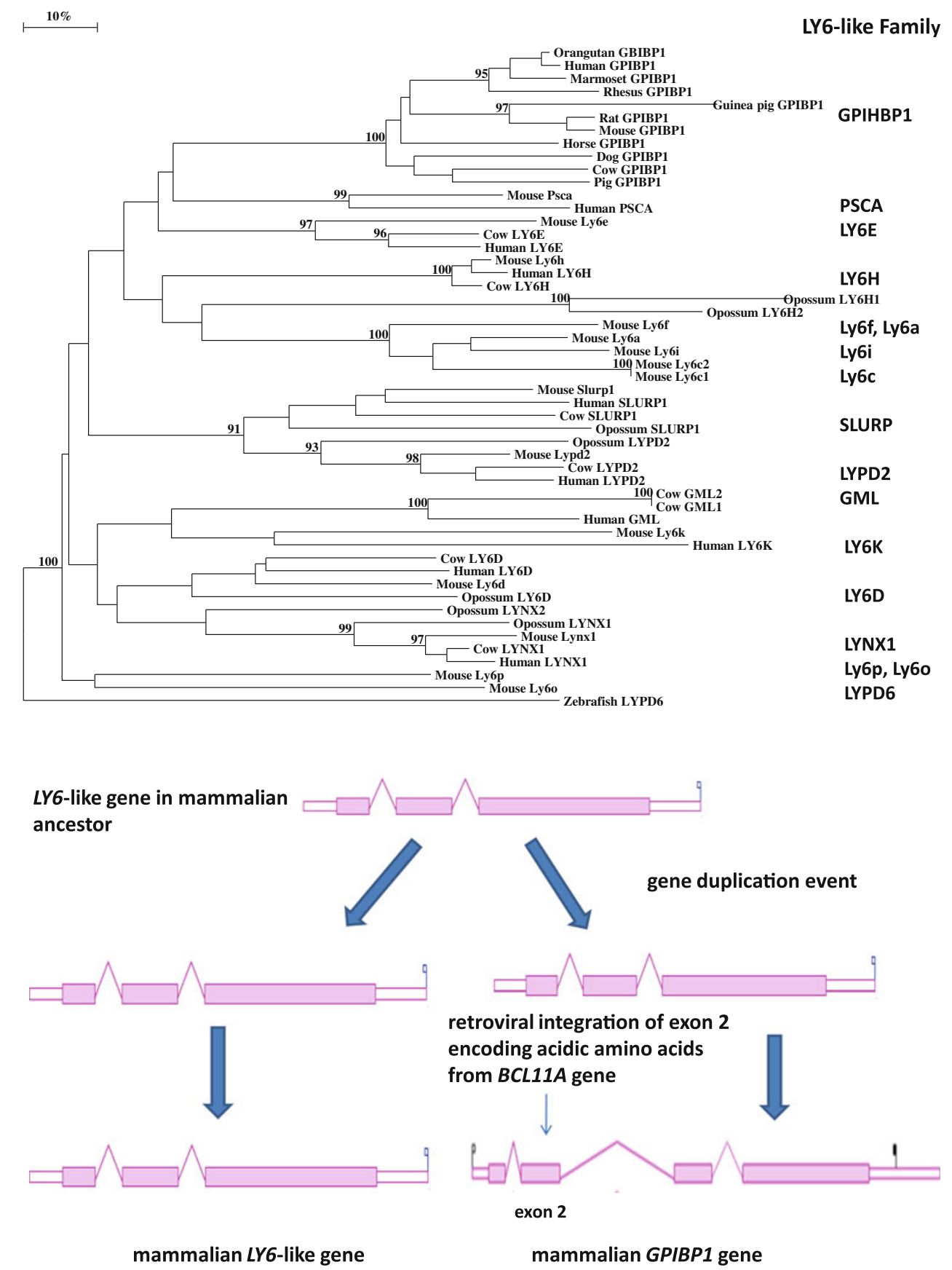

mammalian GPIBP1 gene
Fig. 7 Proposal for generating the GPIHBP1 gene during eutherian mammalian evolution. This hypothesis is for a two-step process for generating the GPIHBP1 gene: (1) a LY6-like gene duplication event in a common ancestor for eutherian mammals; and (2) retroviral transfer of a region of the $B C L 11 A$ gene in the ancestral genome encoding acidic amino acids generating a GPIHBP1-

like gene containing a new exon
484-504 of human B-cell CLL/lymphoma 11A) was identified which encoded an extended sequence of acidic amino acids comparable to amino acid residues 25-50 (corresponding to residues encoded by exon 2 of human GPIHBP1) in the human GPIHBP1 sequence. Supplementary Fig. 1 shows an alignment of this region for representative vertebrate BCL11A acidic amino acid sequences with several mammalian GPIHBP1 exon 2 sequences. Similarities in acidic amino acid sequences are apparent although each protein exhibited a distinctive conservation pattern. It may be noted that the BCL11A gene and protein can be traced back to reptiles and fish in vertebrates (Table 3) whereas GPIHBP1 has been only reported in eutherian mammals (Table 1). Previous studies have shown that the mouse Bcll la gene encodes a $\mathrm{C} 2 \mathrm{H} 2$-type zinc-finger protein which is a common site of retroviral integration in myeloid leukemia and functions as a myeloid and B-cell proto-oncogene (Nakamura et al. 2000) and may serve as a candidate gene for the transfer and integration of the acidic amino acid encoding 'motif' into the mammalian GPIHBP1 gene. A hypothesis concerning the evolutionary appearance of the 'ancestral' eutherian mammalian GPIHBP1 gene is presented in Fig. 7. 
Step 1 An LY6-like gene within a common ancestor to eutherian mammals underwent a tandem duplication event generating two closely related LY6-like genes. It may be noted that the opossum genome contains similar $L Y 6 H$ genes (designated as LY6H1 and $L Y 6 H 2$ ) which are closely localized on opossum chromosome 3 (Fig. 3) and form a distinct opossum LY6-like group following CLUSTAL analysis (Fig. 6); and

Step 2 Retroviral integration of the acidic amino acid encoding 'motif' of the ancestral BCL11A gene may have occurred in one of the duplicated $L Y 6$ like genes (potentially a $L Y 6 H$-like gene or another LY6-like gene) resulting in the addition of an exon (exon 2) which during the subsequent evolution generates an ancestral eutherian mammalian GPIHBPl-like gene and protein which is retained throughout subsequent eutherian mammalian evolution.

\section{Conclusions}

The results of the present study indicate that the mammalian GPIHBPI gene and encoded protein recently reported represents a distinct family of lymphocyte antigen-6 (LYO)related gene and protein which shares key conserved sequences and functions with other LY6-like genes and proteins previously studied (Brakenoff et al. 1995; Capone et al. 1996; Clark et al. 2003; Horie et al. 1998; Ishikawa et al. 2007). GPIHBP1 is encoded by a single gene among the mammalian genomes studied which is localized within a LY6-like gene cluster ( $\sim 500 \mathrm{kbs})$ on human chromosome 8 and usually contained 4 coding exons. Predicted secondary structures for mammalian GPIHBP1 proteins showed a strong similarity with other LY6-like proteins in a number of domains, including the $\mathrm{N}$-terminal signal peptide region, the UPAR-LY6 domain and in having a highly hydrophobic C-terminal helical sequence, which is removed in the endoplasmic reticulum during the formation of the glycosylphosphatidylinositol anchor. In contrast, however, all mammalian GPIHBP1 proteins contained two high acidic amino acid regions, which have been proposed to play a role in binding LPL (Beigneux et al. 2007; Gin et al. 2007, 2011). Predicted secondary and tertiary structures of the UPAR-LY6 mammalian GPIHBP1 domain showed a strong resemblance to the corresponding region for the human CD59 antigen structure (Leath et al. 2007) with five anti-parallel $\beta$-sheets. Comparative studies of 12 mammalian GPIHBP1 genomic sequences indicated that this gene has appeared during eutherian mammalian evolution with conserved genomic sequences observed for all eutherian mammalian genomes examined. In contrast, GPIHBP I gene sequences were absent from the chicken genome or were seen only in part for the monotreme and marsupial genomes examined. It is proposed that the GPIHBP1 gene has appeared early in mammalian evolution following a tandem gene duplication event of one of the LY6 genes and the subsequent retroviral integration of exon 2 encoding the acidic amino acid 'motif'.

Acknowledgments This project was supported by NIH Grants P01 HL028972 and P51 RR013986. In addition, this investigation was conducted in facilities constructed with support from Research Facilities Improvement Program Grant Numbers 1 C06 RR13556, 1 C06 RR15456, 1 C06 RR017515.

Open Access This article is distributed under the terms of the Creative Commons Attribution License which permits any use, distribution and reproduction in any medium, provided the original author(s) and source are credited.

\section{References}

Altschul F, Vyas V, Cornfield A, Goodin S, Ravikumar TS, Rubin EH, Gupta E (1997) Basic local alignment search tool. J Mol Biol 215:403-410

Beigneux AP, Davies BSJ, Gin P, Weinstein MM, Farber E, Qiao X, Peale F, Bunting S, Walzem RL, Wong JS, Blaner WS, Ding Z-M, Melford K, Wongsiriroj N, Shu X, de Sauvage F, Ryan RO, Fong LG, Bensadoun A, Young SG (2007) Glycosylphosphatidylinositol-binding protein 1 plays a critical role in the lipolytic processing of chylomicrons. Cell Metab 5:279-291

Beigneux AP, Gin P, Davies BSJ, Weinstein MM, Ryan OO, Forg LG, Young SG (2008) Glycosylation of Asn-76 in mouse GPIHBP1 is critical for its appearance on the cell surface and the binding of chylomicrons and lipoprotein lipase. J Lipid Res 49:1312-1321

Beigneux AP, Franssen R, Bensadoun A, Gin P, Melford K, Walzem RL, Weinstein MM, Kuienhoven JA, Kastelain JJ, Fong LG, Dallinga-Thie GM (2009a) Cylomicronemia with a mutant GPIHBP1 (Q115P) that cannot bind lipoprotein lipase. Arterioscler Thromb Vasc Biol 29:956-962

Beigneux AP, Gin P, Davies BSJ, Weinstein MM, Bensadoun A, Fong LG, Young SG (2009b) Highly conserved cysteines within the Ly6 domain of GPIHBP1 are crucial for the binding of lipoprotein lipase. J Biol Chem 283:16928-16939

Bovine Genome Project (2008) http://hgsc.bcm.tmc.edu/projects/ bovine

Brakenoff RH, Gerretsen M, Knippels EMC, van Dijk M, van Essen H, Weghuis DO, Sinke RJ, Snow GB, van Dongen GAMS (1995) The human E48 antigen, highly homologous to the murine Ly-6 antigen ThB, is a GPI-anchored molecule apparently involved in keratinocyte cell-cell adhesion. J Cell Biol 129:1677-1689

Capone MC, Gorman DM, Ching EP, Ziotnik A (1996) Identification through bioinformatics of cDNAs encoding thymic shared Ag-1/ stem cell Ag-2: a new member of the human Ly6 family. J Immunol 157:969-973

Chimpanzee Sequencing and Analysis Consortium (2005) Initial sequence of the chimpanzee genome and comparison with the human genome. Nature 437:69-87 
Clark HF, Gurney AL, Abaya E, Baker K, Baldwin D, Brush J, Chen J, Chow B, Chui C, Crowley C, Currell B, Deuel B, Dowd P, Eaton D, Foster J, Grimaldi C, Gu Q, Hass PE, Heldens S, Huang A, Kim HS, Klimowski L, Jin Y, Johnson S, Lee J, Lewis L, Liao D, Mark M, Robbie E, Sanchez C, Schoenfeld J, Seshagiri S, Simmons L, Singh J, Smith V, Stinson J, Vagts A, Vandlen R, Watanabe C, Wieand D, Woods K, Xie MH, Yansura D, Yi S, Yu G, Yuan J, Zhang M, Zhang Z, Goddard A, Wood WI, Godowski P, Gray A (2003) The secreted protein discovery initiative (SPDI), a large-scale effort to identify novel human secreted and transmembrane proteins: a bioinformatics assessment. Genome Res 13:226-2270

Davies BSJ, Beigneux AP, Barnes RH, Yiping T, Gin P, Weinstein MM, Nobumori C, Nyren R, Goldberg I, Olivecrona G, Bensadoun A, Young SG, Fong LG (2010) GPIHBP1 is responsible for the entry of lipoprotein lipase into capillaries. Cell Metab 12:42-52

Eisenhaber B, Bork P, Eisenhaber F (1998) Sequence properties of GPI-anchored proteins near the omega-site: constraints for the polypeptide binding site of the putative transamidase. Protein Eng 11:1155-1161

Emmanuelsson O, Brunak S, von Heijne G, Nielson H (2007) Locating proteins in the cell using TargetP, SignalP and related tools. Nat Protoc 2:953-971

Felsenstein J (1985) Confidence limits on phylogenies: an approach using the bootstrap. Evolution 39:783-791

Fisher EA (2010) GPIHBP1: lipoprotein lipases's ticket to ride. Cell Metab 12:1-2

Franssen R, Young SG, Peelman F, Hertecant J, Sierts JA, Schimmel AW, Bensadoun A, Kastelein JJ, Fong LG, Dallinga-Thie GM, Beigneux AP (2010) Chylomicronemia with low postheparin lipoprotein lipase in the setting of GPIHBP1 defects. Circ Cardiovasc Genet 3:169-178

Fry BG, Wüster W, Kini RM, Brusic V, Khan A, Venkataraman D, Rooney AP (2003) Molecular evolution and phylogeny of elapid snake venom three-finger toxins. J Mol Evol 57:110-129

Gin P, Beigneux AP, Davies B, Young MF, Ryan RO, Bensadoun A, Fong LG, Young SG (2007) Normal binding of lipoprotein lipase, chylomicrons and apo-AV to GPIHBP1 containing a G56R amino acid substitution. Biochim Biophys Acta 1771:1464-1468

Gin P, Beigneux AP, Voss C, Davies SJ, Beckstead JA, Ryan RO, Bensadoun A, Fong LG, Young SG (2011) Binding preferences for GPIHBP1, a glycosylphosphatidylinositol-anchored protein of capillary endothelial cells. Arterio Thromb Vasc Biol 31:176-182

Hall TA (1999) BioEdit: a user-friendly biological sequence alignment editor and analysis program for Windows 95/98/NT. Nucleic Acids Symp Ser 41:95-98

Havel RJ, Kane JP (2001) Introduction: structure and metabolism of plasma lipoproteins. In: Scriver CR, Beaudet AL, Sly WS, Valle D, Childs B, Kinzler KW, Vogelstein B (eds) The metabolic and molecular bases of inherited disease. McGraw-Hill, New York, pp 2705-2716

Horie M, Okutomi K, Ohbuchi Y, Suzuki M, Takahashi E (1998) Isolation and characterization of a new member of the Ly6 gene family (LY6H). Genomics 53:365-368

Horse Genome Project (2008) http://www.uky.edu/Ag/Horsemap/

International Human Genome Sequencing Consortium (2001) Initial sequencing and analysis of the human genome. Nature 409:860-921

Ioka RX, Kang M-J, Kamiyama S, Kim D-H, Magoori K, Kamataki A, Ito Y, Takei YA, Sasaki M, Suzuki T, Sasano H, Takahashi S, Sakai J, Fujino T, Yamamoto TT (2003) Expression cloning, characterization of a novel glycosylphosphatidylinositolanchored high density lipoprotein-binding protein, GPI-HBP1. J Biol Chem 278:7344-7349
Ishikawa N, Takano A, Yasui W, Inai K, Nishimura H, Ito H, Miyagi Y, Nakayama H, Fujita M, Hosokawa M, Tsuchiya E, Kohno N, Nakamura Y, Daigo Y (2007) Cancer-testis antigen lymphocyte 6 complex locus $\mathrm{K}$ is a serological biomarker and a therapeutic target for lung and esophageal carcinomas. Cancer Res 67:11601-11611

Kent WJ, Sugnet CW, Furey TS (2003) The human genome browser at UCSC. Genome Res 12:994-1006

Kimura M (1983) The neutral theory of molecular evolution. Cambridge University Press, Cambridge

Larkin MA, Blackshields G, Brown NP, Chenna R, McGettigan PA, McWilliam H, Valentin F, Wallace IM, Wilm A, Lopez R (2007) Clustal W and Clustal X version 2.0. Bioinformatics 23:2947-2948

Leath KJ, Johnson S, Roversi P, Highes TR, Smith RAG, Mackenzie L, Morgan BP, Lea SM (2007) High-resolution structures of bacterially expressed soluble human CD59. Acta Cryst F63:648-652

Mammalian Genome Project Team (2004) The status, quality, and expansion of the NIH full-length cDNA project: the Mammalian Gene Collection (MGC). Genome Res 14:2121-2127

McGuffin LJ, Bryson K, Jones DT (2000) The PSIPRED protein structure prediction server. Bioinformatics 16:404-405

Mikkelsen TS, Wakefield MJ, Aken B, Amemiya CT, Chang JL, Duke S, Garber M, Gentles AJ, Goodstadt L, Heger A, Jurka J, Kamal M, Mauceli E, Searle SMJ, Sharpe T, Baker ML, Batzer MA, Benos PV, Belov K, Clamp M, Cook A, Cuff J, Das R, Davidow L, Deakin JE, Fazzari MJ, Glass JL, Grabherr M, Greally JM, Gu W, Hore TA, Huttley GA, Kleber M, Jirtle RL, Koina E, Lee JT, Mahony S, Marra MA, Miller RD, Nicholls RD, Oda M, Papenfuss AT, Parra ZE, Pollock DD, Ray DA, Schein JE, Speed TP, Thompson K, VandeBerg JL, Wade CM, Walker JA, Waters PD, Webber C, Weidman JR, Xie X, Zody MC, Broad Institute Genome Sequencing Platform, Broad Institute Whole Genome Assembly Team, Marshall Graves JA, Ponting CP, Breen M, Samollow PB, Lander ES, Lindblad-Toh K (2007) Genome of the marsupial Monodelphis domestica reveals innovation in noncoding sequences. Nature 447:167-175

Mouse Genome Sequencing Consortium (2002) Initial sequencing and comparative analysis of the mouse genome. Nature 420:520-562

Nakamura T, Yamazaki Y, Saiki Y, Moriyaki M, Largaespada DA, Jenkins NA, Copeland NG (2000) Evi9 encodes a novel zinc finger protein that physically interacts with BCL6, a known human B-cell proto-oncogene product. Mol Cell Biol 20:3178-3186

Nosjean O, Briolay A, Roux B (1997) Mammalian GPI proteins: sorting, membrane residence and functions. Biochim Biophys Acta 1331:153-186

Olivecrona G, Ehrenborg E, Semb H, Makoveichuk E, Lindberg A, Hayden MR, Gin P, Davies BS, Weinstein MM, Fong LG, Beigneux AP, Young SG, Harnell O (2010) Mutation of conserved cysteines in the Ly6 domain of GPIHBP1 in familial chylomicronemia. J Lipid Res 51:1535-1545

Ory DS (2007) Chylomicrons and lipoprotein lipase at the endothelial surface: bound and GAG-ged? Cell Metab 5:229-231

Rat Genome Sequencing Project Consortium (2004) Genome sequence of the Brown Norway rat yields insights into mammalian evolution. Nature 428:493-521

Rhesus Macaque Genome Sequencing and Analysis Consortium (2007) Evolutionary and biomedical insights from the Rhesus Macaque genome. Science 316:222-234

Saitou N, Nei M (1987) The neighbour-joining method: a new method for reconstructing phylogenetic trees. Mol Biol Evol 4:406-425

Sendak RA, Bensadoun A (1998) Identification of a heparin-binding domain in the distal carboxyl-terminal region of lipoprotein lipase by site-directed mutagenesis. J Lipid Res 39:1310-1315

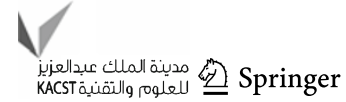


Thierry-Mieg D, Thierry-Mieg J (2006) AceView: A comprehensive cDNA-supported gene and transcripts annotation. Genome Biology 7:S12 http://www.ncbi.nlm.nih.gov/IEB/Research/ Acembly/index.html?human

Van De Peer Y, de Wachter R (1994) TREECON for Windows: a software package for the construction, drawing of evolutionary trees for the Microsoft Windows environment. Comput Appl Sci 10:569-570

Wang J, Hegele RA (2007) Homozygous missense mutation (G56R) in glycosylphosphatidylinositol-anchored high-density lipoprotein-binding protein 1 (GPI-HBP1) in two siblings with fasting chylomicronemia. Lipids Health Dis 6:23
Warren WC, Hillier LW, Marshall Graves JA, Birney E, Ponting CP, Grützner F, Belov K (2008) Genome analysis of the platypus reveals unique signatures of evolution. Nature 453:175-183

Wion KL, Kirchgessner TG, Lusis AJ, Schotz MC, Lawn RM (1987) Human lipoprotein lipase complementary DNA sequence. Science 235:1638-1641

Young SG, Davies BSJ, Fong LG, Gin P, Weinstein MM, Bensadoun A, Beigneux AP (2007) GPIHBP1: an endothelial cell molecule important for the lipolytic processing of chylomicrons. Curr Opin Lipidol 18:389-396 